\title{
A altura facial anterior inferior nas más oclusões do padrão II, deficiência mandibular
}

\author{
Leopoldino Capelozza FILHO*, Sérgio Luiz Menezes Coelho de SOUZA**, Arlete de Oliveira CAVASSAN*, \\ Terumi Okada OZAWA*
}

\begin{abstract}
Resumo
Controvérsias na leitura cefalométrica da AFAi (Altura Facial Anterior inferior) e no diagnóstico clínico baseado na análise facial em casos de más oclusões do padrão II por deficiência mandíbular, motivaram este artigo. Compusemos uma amostra formada por 26 pacientes portadores desta má oclusão, sem distinção de gênero e idade, tratados no curso de especialização da PROFIS do HRAC - USP, Bauru. A amostra foi caracterizada utilizando-se um conjunto de medidas cefalométricas clássicas (SNA, SNB, ANB, NAP, AFAi, SNPO, SNGoGn, CoA, CoGn) e testamos uma forma alternativa para medir a AFAi, onde os pontos espinha nasal anterior (ENA) e mentoniano $(\mathrm{Me})$ foram projetados perpendicularmente a um plano frontal que passa por násio, perpendicular ao plano de Frankfurt (Nperp A) e a distância entre eles medida linearmente. Os resultados foram confrontados com os valores obtidos da medição da AFAi como preconizado por McNamara, em 1984. Encontrou-se uma relação inversa entre a AFAi convencional e a AFAi perpendicular. Esta diferença foi estatisticamente significante para toda a amostra e apresentou alta correlação. A AFAi perpendicular foi sempre menor em toda amostra e exibiu uma tendência de ser tanto menor quanto maior fosse o valor de SNGoGn. Estes achados levaram a crer que a AFAi perpendicular, medida como preconizada neste artigo, torna o triângulo de McNamara mais equilibrado. Isso confere à avaliação cefalométrica a capacidade de identificar a diminuição da AFAi, característica facial típica do portador de deficiência mandibular, além de permitir um entendimento mais claro dos efeitos do tratamento nessa dimensão.
\end{abstract}

Palavras-chave: Má oclusão. Padrão II. Classe II. Cefalometria.

\section{INTRODUÇÃO}

A análise cefalométrica clássica tem alguma aplicação naqueles casos onde a má oclusão é dento-alveolar e a resolução do problema pode ser feita utilizando-se recursos da Ortodontia convencional. Todavia existe uma grande diferença entre este tipo de Ortodontia dirigida especificamente para a correção de desordens dento-alveolares e aquela que se beneficia de recursos de ortopedia mecânica e/ou funcional e cirurgia ortognática.

O ortodontista desejando oferecer estas opções ao seu paciente necessita analisar as discrepâncias basais por uma ótica diferente. Uma má oclusão dento-esquelética do padrão II $^{9}$, por exemplo, pode ser o resultado de uma combinação de múltiplos fatores, cuja exata definição pela cefalome-

\footnotetext{
* Ortodontistas do Hospital de Reabilitação de Anomalias Craniofaciais da Universidade de São Paulo (HRAC-USP), Bauru-SP.

** Aluno do Curso de Especialização em Ortodontia do HRAC-USP, Bauru-SP.
} 
tria convencional é quase impossível ${ }^{8}$.

A definição de Classe II, divisão 1, como uma má oclusão sagital, com base na relação dos primeiros molares permanentes é portanto absolutamente dentária. Porém, desde sempre, mesmo no início do século passado, apesar dos ortodontistas terem uma visão exclusivamente oclusionista, talvez até pelos métodos disponíveis, a estética já era uma preocupação no planejamento do tratamento ortodôntico ${ }^{1}$.

A Ortodontia ainda incipiente, buscava uma forma mais adequada para relacionar os dentes com o complexo craniofacial e, desta maneira, emprestou dos anatomistas e antropologistas, alguns planos e ângulos craniométricos. Essas medidas ampliaram os horizontes dos ortodontistas na procura de meios de diagnósticos mais eficazes. Com a criação do cefalostato, a cefalometria radiográfica foi introduzida no diagnóstico ortodôntico. A partir daí, diversos estudos foram realizados no campo da Radiologia, na melhoria das técnicas radiográficas e permitiram à Ortodontia estudos do desenvolvimento craniofacial, criando padrões até hoje utilizados no aprimoramento da Ortodontia como ciência ${ }^{5}$.

Com o advento da cefalometria várias análises foram desenvolvidas na tentativa de qualificar e quantificar a estética facial. Nestas análises, as medidas obtidas a partir do perfil esquelético foram utilizadas também para analisar o grau de harmonia facial a fim de diferenciar o perfil facial harmônico do desarmônico $7,10,12,13,15,18,19,22,23,24,27$. Padrões e ideais cefalométricos foram criados e a riqueza de detalhes da telerradiografia, em norma lateral, precisou ser mensurada para que esta fosse tangível aos ortodontistas neófitos.

Particularmente importante é considerar que os valores cefalométricos normativos têm sido identificados como guias no diagnóstico e na movimentação dentária ${ }^{13,17,18}$. A análise cefalométrica tem sido usada como um padrão pela facilidade de obtenção, medição e comparação (superposição) das estruturas esqueléticas e baseada na crença de que seguir as normas cefalométricas resulta em uma face harmoniosa ${ }^{2,3,4,8}$. Estas distin- tas vantagens da análise cefalométrica levaram a uma forte confiabilidade na cefalometria em todos os aspectos do tratamento ortodôntico. Durante muitos anos, os ideais cefalométricos foram os pontos cardeais para o tratamento ortodôntico e sinônimo de estética facial. A tridimensionalidade das estruturas faciais foi compactada na imagem bidimensional da telerradiografia e isto foi aceito de forma simplista, até que notou-se que os valores cefalométricos advindos das médias obtidas dos estudos cefalométricos não se aplicavam a todos os indivíduos. O impacto do tratamento sobre a face, visando o ideal cefalométrico começou a ser questionado. As conclusões foram que o tratamento ortodôntico baseado apenas em análise de modelos e/ou padrões cefalométricos sem o exame facial, não seria adequado ${ }^{14}$.

Muitas possíveis explicações existem para a inadequação da cefalometria. A suposição de que a correção oclusal, baseada nos padrões cefalométricos leva à estética facial não é sempre verdadeira e pode em alguns casos, levar a um resultado estético insatisfatório ${ }^{2,14,16,17,29}$. Michiels e Tourne ${ }^{20}$ estudaram 27 pacientes Classe I que não haviam sido tratados ortodonticamente, a fim de testar a validade de várias análises cefalométricas, mais comumente utilizadas para prognosticar um perfil clínico. Suas conclusões foram que as medidas envolvendo os pontos da base craniana são imprecisos na definição do real perfil clínico, as medidas envolvendo as relações intermaxilares são levemente mais precisas na definição do verdadeiro perfil, nenhuma medida é 100\% precisa e a espessura do tecido mole e a inclinação axial dos incisivos são as variáveis mais imprecisas.

Quando diferentes análises cefalométricas são utilizadas para avaliar um mesmo paciente, diferentes diagnósticos, planos de tratamentos e resultados podem ser encontrados. Esta disparidade torna um plano de tratamento, com má oclusão esquelética baseado totalmente na análise cefalométrica, desaconselhável. Wylie et al. ${ }^{29}$ analisaram 10 pacientes utilizando cinco das mais habituais análises cefalométricas e encontraram apenas 40\% 
de concordância nos planos de tratamento. Eles concluiram, e veja que isto foi em 1950, que a cefalometria não deveria ser a ferramenta primária para o diagnóstico dentofacial. Talvez a cefalometria seja mais confiável para as alterações dos tecidos, quando não exista discrepância esquelética. Muitas análises cefalométricas são baseadas em amostras de indivíduos que não apresentam discrepâncias esqueléticas. Quando estes "valores normais" de uma população normal são aplicados para as desarmonias verticais e ântero-posteriores eles perdem a validade.

A análise facial aprimora o diagnóstico e o planejamento do tratamento ortodôntico e deve ser soberana aos meios auxiliares de diagnóstico na determinação das metas terapêuticas. Uma compreensão conjunta da análise facial e cefalometria parece ser o ideal no momento. A interação, a interrelação, o complemento ou até o ajuste corretivo da cefalometria pela análise facial são as lições que estamos aprendendo.

Nesta linha, daremos atenção neste trabalho à avaliação do terço inferior da face, como preconizado por McNamara Jr. ${ }^{18}$, baseada numa proposta de Harvold. Utilizada para avaliar o componente vertical da relação maxilo-mandibular, esta avaliação parece ser muito influenciada pelo posicionamento espacial das bases apicais, principalmente a mandibular. Nos casos de más oclusões dento-esqueléticas, pode haver um contraste entre a distância ENA-Me, obtida na cefalometria, daquela verificada clinicamente durante a análise facial ${ }^{8,9}$.

Quando existe uma discrepância sagital entre as bases apicais, os pontos ENA e Me, estão desalinhados e a distância entre eles tende a aumentar à medida em que estão mais afastados, por uma questão meramente geométrica (Fig. 1). O resultado pode ser um aumento na AFAi, sem que tenha havido incremento vertical. Isso é diferente do encontrado clinicamente e cria um antagonismo entre o diagnóstico ditado pela análise cefalométrica e a conduta clínica adotada. Nossa proposta foi avaliar esta situação e propor alternativas para conduta e interpretação dos valores obtidos cefalométrica e clinicamente.

\section{MATERIAL E MÉTODOS}

Examinou-se 26 telerradiografias de pacientes tratados no curso de especialização da PROFISHRAC, USP, Bauru de ambos os gêneros e sem limite de idade, diagnosticados e tratados como se fossem portadores de más oclusões do padrão II, Classe II divisão 1, por deficiência mandibular. O critério para inclusão do paciente na amostra foi fundamentado no diagnóstico encontrado no prontuário do paciente e o tipo de tratamento recebido: terapia de avanço mandibular, por estímulo de crescimento. O examinador somente teve acesso a esses dados para a seleção, não tendo sido analisados nesse momento as telerradiografias em norma lateral e as fotos dos pacientes.

As telerradiografias dos pacientes selecionados foram então separadas. Elas faziam parte da docu-

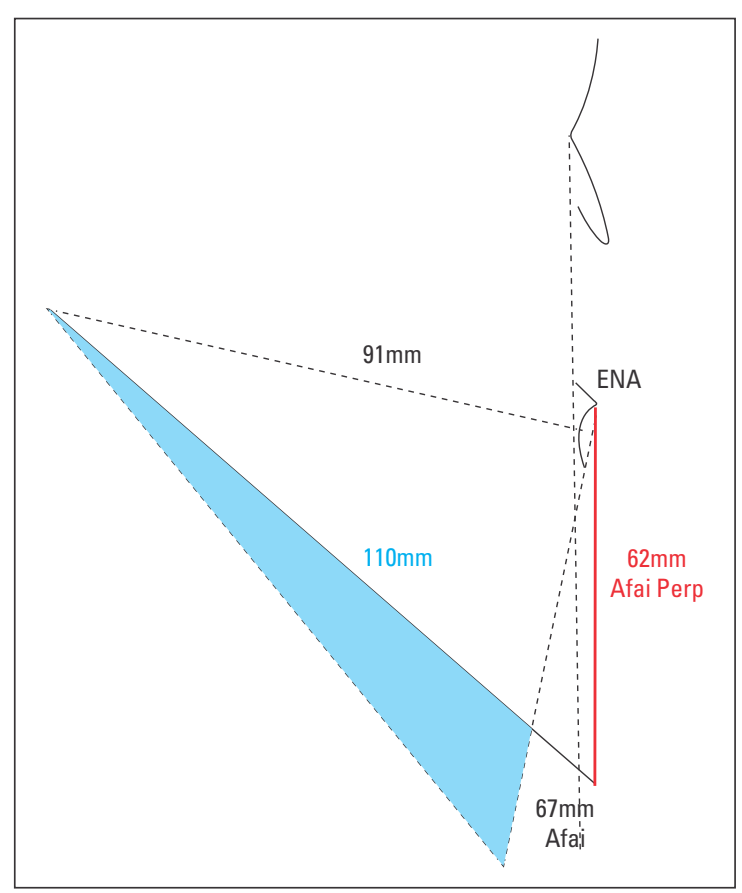

FIGURA 1 - Em um paciente normal a divergência entre os valores obtidos para a altura facial anterior inferior é pequena ou quase nula, porém nos casos de pacientes portadores de Classe II, divisão1, por deficiência mandibular, essa divergência é significante e se torna ainda maior quanto maior for a rotação horária da mandíbula. 
mentação de rotina e tinham sido obtidas em norma lateral, em um aparelho Rotograph Plus, regulado para exposição de $70 \mathrm{KVp}, 10 \mathrm{~mA}$, tempo de exposição de 1,0 segundo e uma distância focal de $1,52 \mathrm{~m}$ de acordo com a técnica adotada universalmente ${ }^{5}$.

As telerradiografias em norma lateral foram traçadas em papel ultrafan seguindo o traçado cefalométrico padrão PROFIS, com a modificação introduzida para a medição da altura facial ânte- ro-inferior. A medida da AFAi perpendicular foi obtida através do valor da distância linear entre os pontos ENA e Me projetados perpendicularmente à linha N-perpendicular. Os resultados destas medições foram comparados aos resultados das medições obtidas pelo método convencional de avaliação da altura facial ântero-inferior ${ }^{18}$ (Fig. 2). Destes traçados, extraímos os dados cefalométricos necessários para esta pesquisa que foram: relação das bases apicais (SNA, SNB, ANB, NAP, CoA, CoGn,

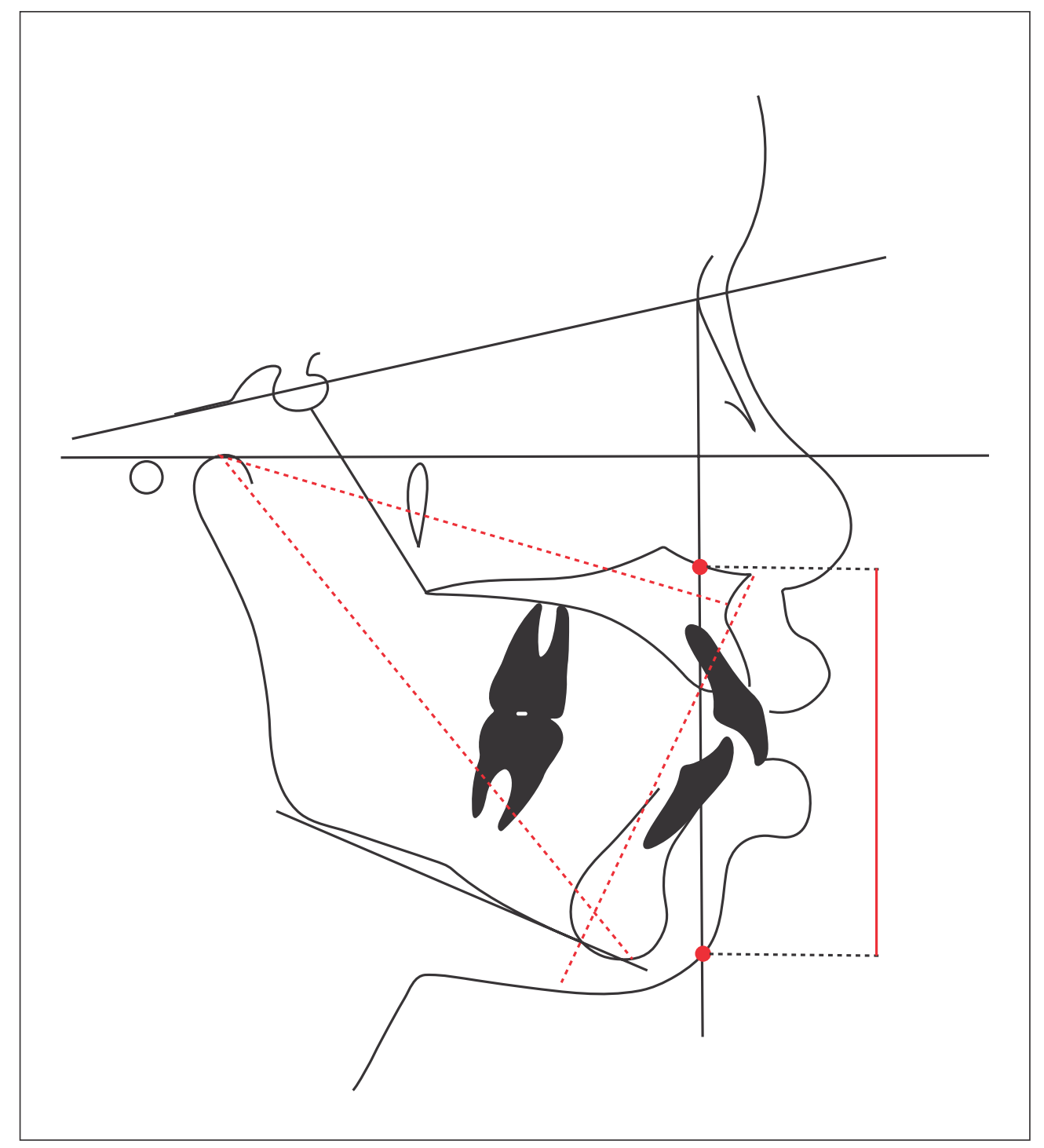

FIGURA 2 - A medida da AFAi perpendicular foi obtida através do valor da distância linear entre os pontos ENA e Me projetados perpendicularmente à linha $\mathrm{N}$-perpendicular. 
AFAi Nperp-A) e orientação do crescimento facial (SNGn, SNGoGn, SN P.ocl). A medida da AFAi perpendicular foi obtida através do valor da distância linear entre os pontos ENA e Me projetados perpendicularmente à linha $\mathrm{N}$-perpendicular ( $\mathrm{N}$-perp). Os resultados destas medições foram comparados aos resultados obtidos pelo método convencional de avaliação da altura facial ântero-inferior ${ }^{18}$ (Fig. 2). A fim de avaliar a confiabilidade dos valores obtidos, os traçados e as medições foram refeitas e a análise de erros causais foi realizada pelo método de Dalhberg $^{11}$ (Tab. 4).

\section{RESULTADOS}

Os valores cefalométricos, assim como os valores para os dois métodos de medição da altura facial ântero-inferior estão na tabela 1. Os valores cefalométricos médios, mínimos, máximos e respectivos desvios-padrão das variáveis estudadas estão distribuídos na tabela 2. Durante o processo

\begin{tabular}{|c|c|c|c|c|c|c|c|c|c|c|}
\hline & & 775 & 95 & 17 & 675 & कर & 85 & 105 & 15 & T) \\
\hline 1. & 87 & 77,5 & 9,5 & 17 & 67,5 & 63 & 85 & 105 & 15 & 32 \\
\hline 2. & 84 & 80 & 4 & 5 & 67 & 63 & 91 & 115 & 17 & 28 \\
\hline 3. & 79 & 72,5 & 6,5 & 9 & 59 & 66 & 90 & 99 & 22 & 46 \\
\hline 4. & 80 & 73,5 & 6,5 & 11 & 76 & 66 & 98 & 122 & 13 & 40 \\
\hline 5. & 74 & 70 & 4 & 2 & 68 & 64 & 84,5 & 102 & 19 & 38,5 \\
\hline 6. & 79 & 74 & 5 & 10 & 73 & 67 & 83 & 116 & 20 & 41 \\
\hline 7. & 81 & 75 & 6 & 10 & 64 & 60 & 84 & 106 & 8 & 33 \\
\hline 8. & 80 & 72,5 & 7,5 & 12,5 & 65 & 62,5 & 94 & 110 & 11 & 35 \\
\hline 9. & 83 & 76 & 7 & 15 & 60 & 56 & 93 & 108 & 12 & 34 \\
\hline 10. & 83,5 & 75,5 & 8 & 3,5 & 74 & 67 & 95 & 116 & 9 & 39 \\
\hline 11. & 83 & 77 & 6 & 10 & 67 & 65 & 97 & 117 & 15 & 34 \\
\hline 12. & 89 & 84,5 & 4,5 & 8 & 56 & 53 & 90 & 108 & 5 & 20 \\
\hline 13. & 83 & 77,5 & 5,5 & 9 & 77 & 63 & 88 & 113 & 14 & 36 \\
\hline 14. & 82 & 77,5 & 4,5 & 7 & 76 & 73,5 & 93 & 124 & 11,5 & 32 \\
\hline 15. & 82 & 76 & 6 & 16 & 57 & 54 & 89 & 104 & 18,5 & 34 \\
\hline 16. & 86 & 80,5 & 5,5 & 6 & 67 & 65 & 103,5 & 128 & 3,5 & 27,5 \\
\hline 17. & 83 & 81 & 2 & $-2,5$ & 63 & 62 & 90 & 117 & 5 & 24 \\
\hline 18. & 83 & 74 & 9 & 16 & 67 & 62 & 91 & 110 & 19 & 40 \\
\hline 19. & 84 & 76 & 8 & 7 & 84 & 76 & 93 & 126 & 9 & 39 \\
\hline 20. & 86 & 78 & 8 & 17 & 62 & 53 & 88 & 106 & 16 & 32 \\
\hline 21. & 83 & 77,5 & 5,5 & 9 & 70,5 & 68 & 86 & 112 & 16 & 39 \\
\hline 22. & 82 & 77 & 5 & 8 & 62 & 58 & 98 & 115 & 11,5 & 29,5 \\
\hline 23. & 83 & 76 & 7 & 12,5 & 59 & 55 & 88 & 103 & 16 & 32 \\
\hline 24. & 79 & 72 & 7 & 12 & 67 & 61,5 & 91 & 109 & 18 & 37 \\
\hline 25. & 82 & 77 & 5 & 9,5 & 67 & 65 & 103 & 120 & 11 & 21,5 \\
\hline 26. & 80 & 73 & 7 & 13 & 65 & 60 & 99 & 118 & 19 & 34 \\
\hline
\end{tabular}

\begin{tabular}{|c|c|c|c|c|}
\hline VARIÁVEL & MÉDIA & MÍNIMA & MÁXIMA & DESVIO PADRÃO \\
\hline SNA & 82,32 & 74,00 & 89,00 & 2.99 \\
\hline SNB & 76,19 & 70,00 & 84,50 & 3.15 \\
\hline ANB & 6,13 & 2,00 & 9,50 & 1.69 \\
\hline NAP & 9,71 & $-2,50$ & 17,00 & 4.06 \\
\hline AFAl* $^{*}$ & 66,92 & 56,00 & 84,00 & 6.72 \\
\hline AFAI PERP* & 62,63 & 53,00 & 76,00 & 5.67 \\
\hline COA & 91,73 & 83,00 & 103,50 & 5.55 \\
\hline $\mathrm{COGn}$ & 112,65 & 99,00 & 128,00 & 7.66 \\
\hline SNPO & 13,61 & 3,500 & 22,00 & 4.99 \\
\hline SNGOGn & 33,76 & 20,00 & 46,00 & 6.13 \\
\hline
\end{tabular}


das medições, observou-se que quanto maior era o valor para SNGoGn, maior era a diferença entre os valores para AFAi convencional e AFAi perpendicular. Os valores para AFAi convencional, AFAi perpendicular, foram avaliados estatisticamente segundo o teste "t" de Student a uma significância de $5 \%$ e correlacionados aos valores de $\mathrm{SNGoGn}$. Estes dados, as médias, desvios-padrão, valor p e o valor t estão incluídos nas tabelas 2 e 3 . O resultado da análise dos erros causais e sistemáticos está na tabela 4 e não ocorreu erro sistemático ou causal.

\section{DISCUSSÃO}

Com o objetivo de caracterizar a amostra e apoiado nos valores médios encontrados para as grandezas cefalométricas (Tab. 1), os indivíduos portadores de uma relação molar de Classe II,

\begin{tabular}{|c|c|c|c|}
\hline Variável & SnGoGn & AFAi & AFAi-perp \\
\hline SnGoGn & 1,0000 & $\begin{array}{c}2875 \\
p=, 154\end{array}$ & $\begin{array}{c}, 3287 \\
p=, 101\end{array}$ \\
\hline Afai & $\begin{array}{c}, 2875 \\
p=, 154\end{array}$ & 1,0000 & $\begin{array}{c}9659 \\
p=, 000\end{array}$ \\
\hline AFAi-perp & $\begin{array}{c}, 3287 \\
p=, 101\end{array}$ & $\begin{array}{c}9659 \\
p=, 000\end{array}$ & 1,0000 \\
\hline
\end{tabular}

divisão 1 , aqui examinados, apresentaram a maxila bem posicionada e a mandíbula retroposicionada em relação à base craniana. O comprimento efetivo das bases apicais, aceitando a maxila como normal, acrescenta ao descrito acima, uma deficiência mandibular média de 3 milímetros. Portanto, cefalometricamente uma amostra de portadores de degrau sagital maxilo-mandibular aumentado (padrão II) ${ }^{9}$, deficiência mandibular, com relação molar de Classe II, divisão 1. A relação entre as bases apicais teve um resultado condizente com o tipo de má oclusão $(\mathrm{ANB}=6,0)$ assim como o ângulo da convexidade facial típico da má oclusão de Classe II (NAP=9,7). A direção de crescimento facial mostrou uma moderada tendência vertical, mostrando um valor médio de $33,76^{\circ}$ e grande variação na amostra, com um mínimo de $20^{\circ}$ e máximo de $46^{\circ}$. Utilizamos o ângulo do plano mandibular para esta amostra, porque nos casos de más oclusões com discrepâncias esqueléticas como os casos de Classe II, aqui avaliados, ele é mais confiável para determinar a direção de crescimento do que o eixo facial. A mandíbula por estar deficiente, tenderá a abrir o eixo facial.

A avaliação da Altura Facial Anterior inferior, como preconizado por McNamara Jr. ${ }^{18}$, mostrou valores maiores que o normal, com significância

\begin{tabular}{|c|c|c|c|c|c|c|c|}
\hline \multirow[b]{2}{*}{ Medida } & \multirow[b]{2}{*}{ Erro } & \multicolumn{2}{|c|}{$1^{\text {a }}$ Medição } & \multicolumn{2}{|c|}{$2^{\mathrm{a}}$ Medição } & \multirow[b]{2}{*}{$\mathbf{t}$} & \multirow[b]{2}{*}{$\mathbf{p}$} \\
\hline & & Média & DP & Média & DP & & \\
\hline SNA & 0,46 & 82,10 & 3,06 & 82,29 & 2,91 & 1,547 & 0,134 \\
\hline SNB & 0,37 & 76,21 & 3,22 & 76,15 & 3,02 & 0,550 & 0,587 \\
\hline ANB & 0,57 & 5,94 & 1,85 & 6,19 & 1,76 & 1,639 & 0,114 \\
\hline NAP & 1,13 & 9,29 & 4,35 & 9,83 & 3,83 & 1,795 & 0,085 \\
\hline AFAI & 0,57 & 66,75 & 6,85 & 66,77 & 6,71 & 0,120 & 0,906 \\
\hline AFAI PERP & 0,37 & 62,77 & 5,53 & 62,69 & 5,78 & 0,750 & 0,461 \\
\hline CoA & 0,62 & 91,56 & 5,55 & 91,63 & 5,69 & 0,440 & 0,664 \\
\hline CoGn & 0,62 & 112,48 & 7,90 & 112,50 & 7,69 & 0,110 & 0,913 \\
\hline SNPo & 0,50 & 13,60 & 4,84 & 13,58 & 5,00 & 0,137 & 0,892 \\
\hline SNGoGn & 0,33 & 33,67 & 6,09 & 33,83 & 6,03 & 1,775 & 0,088 \\
\hline
\end{tabular}

Não houve erro sistemático

0 erro casual (Dahlberg) é o mostrado na coluna Erro 
estatística, em nossa amostra. Porém quando esta avaliação foi feita pela AFAi perpendicular os valores foram menores que o normal, gerando uma média de 62,63mm (Tab. 2). Além disso houve no teste de correlação entre a AFAi clássica e AFAi, perpendicular, uma variação inversa entre elas, ou seja, quando a AFAi perpendicular diminuía, a AFAi clássica aumentava. Considerando que os pacientes, para esta amostra, foram diagnosticados como portadores de má oclusão de Classe II, divisão 1 , com participação mandibular e tratados com avanço da mandíbula, admite-se que um dos objetivos terapêuticos era o aumento da altura facial anterior inferior. Esta ocorrência bastaria para indicar que a informação diagnóstica (deficiência na
AFAi) fornecida pela AFAi perpendicular é mais consistente com o método terapêutico adotado que provoca aumento na AFAi. Ao contrário, a AFAi convencional sugeriu um aumento incompativel com a terapia de avanço mandibular e conseqüente aumento inexorável da altura facial anterior inferior.

Esmiuçando este aspecto na amostra examinada, vemos que esta correlação inversamente proporcional é obtida principalmente devido aos pacientes com tendência de crescimento vertical (GoGnSN aumentado). Nos pacientes horizontais, a discrepância entre as avaliações da AFAi é menor.

Considerando os pacientes com GoGnSN a $37^{\circ}$, (pacientes $\mathrm{n}^{\circ} 3,4,6,10,18,19,21,24$, Tab. 1)
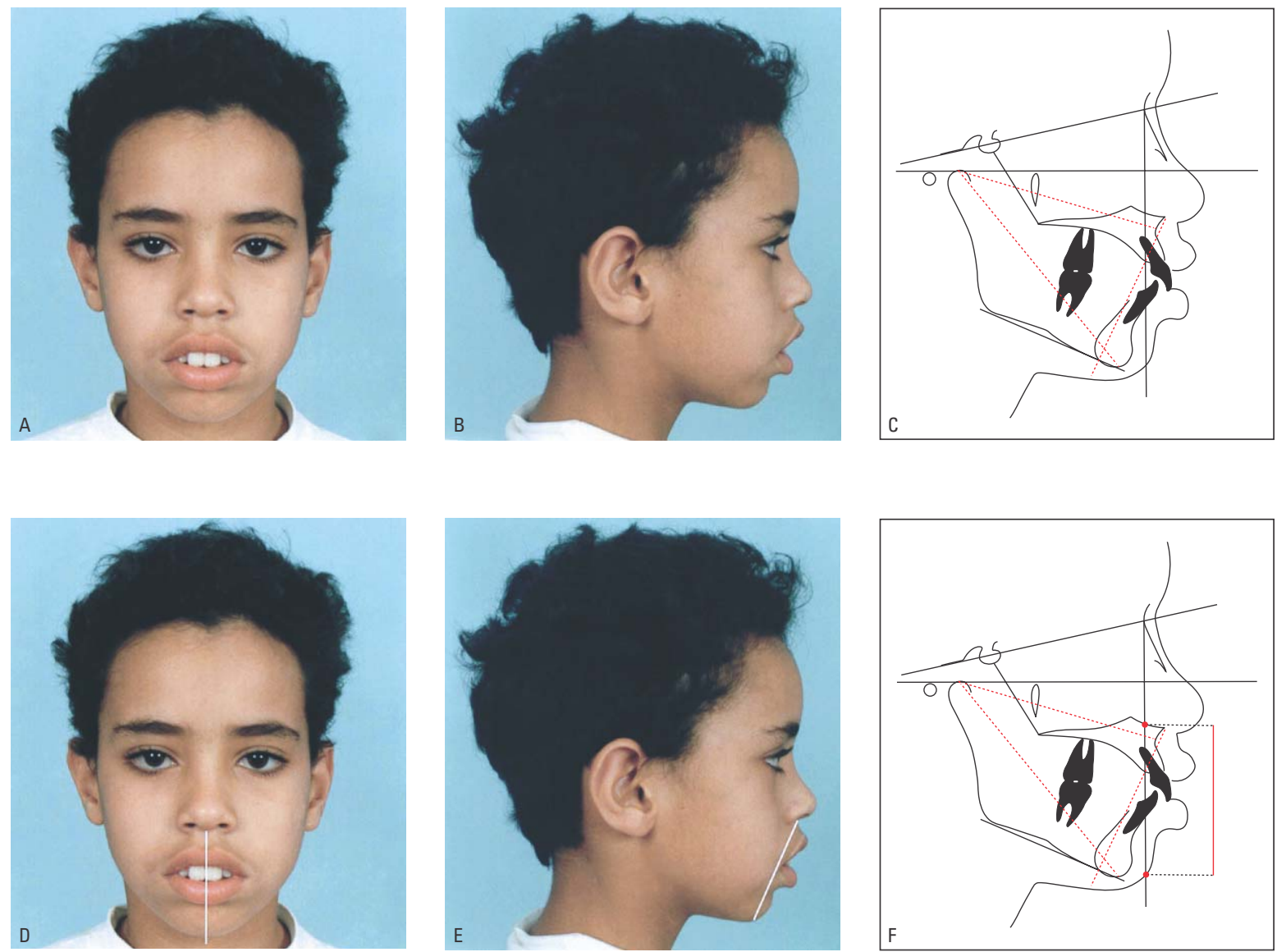

FIGURA 3 - A AFAi, quando avaliada por uma perspectiva lateral, causa a ilusão de estar maior do que quando avaliada por uma perspectiva frontal. Esta (frontal) mais consistente com a terapia ortodôntica adotada de avanço mandibular (3A, B, C). A mesma distância linear medida para a AFAi convencional ultrapassa a distância medida para a AFAi perpendicular. 
vemos que os valores para AFAi perpendicular foram bem menores do que os obtidos para a AFAi clássica. Tomando o paciente 18 como exemplo, a diferença entre a AFAi perpendicular e a AFAi clássica foi de $5 \mathrm{~mm}$. O valor obtido neste caso para a AFAi clássica é capaz de complicar a definição do diagnóstico com base na cefalometria e de desestimular a adoção de uma terapia para avanço mandibular enquanto que o ditado pela AFAi perpendicular é consistentemente relacionado com o problema apresentado pelo paciente e pela terapia necessária para corrigí-la (Fig. 3).

Em termos gerais, o que se pretende definir é que a avaliação maxilo-mandibular, conforme preconizado por McNamara Jr. ${ }^{18}$, deverá utilizar, em pacientes portadores de más oclusões do padrão II, deficiência mandibular, Classe II, a AFAi perpendicular. O diagnóstico assim obtido teria menos chance de erro por não ser deturpado pelos milímetros de deficiência mandibular que afastam o ponto Me do ponto ENA no sentido horizontal, mas são somados e avaliados como altura facial ântero-inferior (Fig. 3D, E, F).

Pelo exposto fica claro que a adoção da AFAi perpendicular aqui proposta, derivada do conceito de se avaliar a AFAi como no método da aná- lise facial ou seja, em um plano vertical, resgata a eficiência do triângulo de McNamara $\mathrm{Jr}^{18} \mathrm{em}$ pacientes portadores de Classe II, divisão 1, por deficiência mandibular (Fig. 3A, B, C).

\section{CONCLUSÃO}

A avaliação maxilo-mandibular, conforme preconizado por McNamara $\mathrm{Jr}{ }^{18}$, deveria ser modificada quando adotada para complemento diagnóstico ou avaliação de resultado terapêutico em portadores de más oclusões do padrão II, Classe II, deficiência mandibular. Nestes, a AFAi clássica (distância entre ENA e Me), deveria ser substituída pela AFAi perpendicular, tomada pela projeção dos mesmos pontos (ENA e Me), em um plano vertical.

Emprestando da análise facial o conceito de fazer avaliação vertical em um plano vertical, estirparíamos da avaliação da AFAi erros trazidos por alterações dimensionais horizontais, no caso específico aqui tratado, da mandíbula. A vantagem auferida é um diagnóstico consistente com a alteração morfológica encontrada nestes pacientes e com a conduta terapêutica a ser adotada, ou em outras palavras, diagnóstico de deficiência mandibular e diminuição da AFAi. 
values from ALFH measurements as dictated by McNamara, 1984. We found a reverse relationship between the different measurements (conventional ALFH and ALFH perpendicular). This reverse relationship were statistically significant to whole sample and showed a high correlation. The ALFH perpendicular was always minor than conventional ALFH and exhibited a tendency to be even minor, as higher as were the value obtained to SNGoGn angle. These findings leaded to believe that the ALFH perpendicular, used as preconized in this article, turns the McNamara triangle more balanced and consequently its obtained diagnostic in more concordance with the orthodontic therapy adopted to correct the Class II division 1 with mandibular deficiency

Key words: Malocclusion. Class II. Cephalometry.

\section{REFERÊNCIAS}

1. ANGLE, E. H. Maloclusion of the teeth. 7th ed. Philadelphia: $\mathrm{S}$ S. White, 1907

2. ARNETT, G. W.; BERGMAN, R.T. Facial keys to orthodontic diagnosis and treatment planning - part II. Am J Orthod Dentofacial Orthop, St. Louis, v.103, no. 5, p. 395-411, May 1993

3. AUGER,T. A.;TURLEY, P. K. The female soft tissue profile as presented in fashion magazines during the 1900: a photographic analysis. Int J Adult Orthodon Orthognath Surg, Chicago, v. 4 , no.1, p. 7-18, 1999

4. BITTNER, C.; PANCHERS, H. Facial morphology and malocclusions. Am J Orthod Dentofacial Orthop, St. Louis, v. 97, no. 4, p. 303-315, Apr. 1990

5. BROADBENT, B. H. et al. Bolton standarts of dentofacial developmental growth. St. Louis: C. V. Mosby, 1975.

6. BRODIE, A. G. On the growth pattern of the human head from the third monta to the eight year of life. Am J Anat, Philadelphia, v. 68, p. 209-262, 1941

7. BUTOW, K. W. MULLER, W. G. MUELENAERE, J J. G. G. Profile cefalometric analysis: a combination of the cephalophotometric and the architectural-structural craniofacial analyses. Int J Adult Orthodon Orthognath Surg, Chicago, v. 4, no. 2 p. 87-104, 1989.

8. CAPELOZZA FILHO, L.; ALMEIDA, G. A.; MAZOTTINI NETO R. J.C Maxillomandibular relationships in patients with dentofacial deformities diagnostic criteria utilizing three cephalometrics analysis. Int J Adult Orthodon Orthognath Surg, Chicago, v. 4, no.1, p. 13-26. 1989.

9. CAPELOZZA FILHO et al. Diagnóstico em Ortodontia. 1. ed Maringá: Ed. Dental Press, 2004.

10. COX, N. H. VAN DER LINDEN, F. P. G. M. Facial harmony. Am J Orthod, St. Louis, v. 60, no. 2, p. 175-183, Aug. 1971.

11. DAHLBERG, G. Statistical methods for medical and bilogical student. New York: Intersciense, 1940

12. HOLDAWAY, R. A. A soft tissue cephalometric analysis and its use in orthodontic treatment planning Part I. Am J Orthod, St. Louis, v. 84, no. 1, p.1-28, July 1983.

13. HOLDAWAY, R. A. A soft tissue cephalometric analysis and its use in orthodontic treatment planning. Part II. Am J Orthod, St. Louis, v. 85, no. 4, p. 279-293, Apr. 1984

14. JACOBSON, A. Planning for orthognathic surgery- art or science? Int J Adult Orthodon Orthognath Surg, Chicago, v. 5, no. 4, p. 217-224, 1990

15. KROGMAN, W. H.; SASSOUNI, V. A syllabus in roentgenographic cephalometry. Philadelphia: Philadelphia Center for Research in Child Growth, 1957.

16. LEGAN, H. L.; BURSTONE, C. J.; CONN, F. Soft tissue cephalometric analysis for orthognatic surgery. J Oral Surgery, Chicago, v. 38 , no.10, p. 744-751, Oct. 1980 .
17. LEHMAN, J. A. Soft tissue manifestations of aesthetic defects of jaws: Diagnosis and treatment. Clin Plast Surg, Philadelphia, v. 14, no. 4, p. 767-783, Oct. 1987.

18. McNAMARA Jr., J. A. A method for cephalometric evaluation. Am J Orthod, St. Louis, v. 86, no. 5, p. 449-469, Nov.1984.

19. MERRIFIELD, L. L. The profile line as an aid in critically evaluating facial esthetics. Am J Orthod, St. Louis, v. 57, no. 11 p. 804-822, Nov.1966

20. MICHIELS, L. Y. F.; TOURNE, L. P. M. Nasion true vertical: a proposed method for testing the clinical validity of cefalometric measurements applied to a new cephalometric reference line. Int J Adult Orthodon Orthognath Surg, Chicago, v. 5, no. 1, p. 43-52, 1990.

21. NGUYEN, D. D; TURLEY, P. K. Changes in the Caucasian male facial profile as depicted in fashion magazines during the twentieth century. Am J Orthod, St. Louis, v.114, p. 208-17, Aug.1998

22. RICKETTS, R. M. The influence of orthodontic treatment of facial growth and development. Angle Orthod, Appleton, v. 30, no. 1 , p. 103-53, Jan. 1960

23. RIEDEL, R. A. Esthetics and its relation to orthodontic therapy. Angle Orthod, Appleton, v. 20, no. 3, p. 168-178, July 1950.

24. SHEIDERMAN, G. B.; BELL, W. H.; LEGAN, H. L.; FINN, R. A.; REISCH, J. S. Cephalometric analysis of dentofacial normals. Am J Orthod, St. Louis, v. 78, no. 4, p. 404-420, 1980.

25. SICHER, H.; DU BRUL, E. L. Anatomia descritiva e funcional. In: Anatomia bucal. 6. ed. Rio de Janeiro: Guanabara Koogan 1977. cap. 2, p. 6-125

26. DE SMIT, A.; DERMAUT, L. Soft tissue profile preference. Am J Orthod, St. Louis, v. 86, no.1, p. 67-73, July 1984.

27. STEINER, C. E. Cephalometrics for you and me. Am J Orthod, St. Louis, v. 3, 9, no. 10, p. 720-755, Oct.1953.

28. SUBTELNY, J. D. The soft tissue profile, growth and treatment changes. Angle Orthod, Appleton, v. 31, no. 1, p.105-122, Apr. 1961.

29. WYLIE, G. A.; FISH, L. C.; EPKER, B. N. Cephalometrics: a comparison of five analyses currently used in diagnosis of dento facial deformities. Int J Adult Orthodon Orthognath Surg, Chicago, v. 2, no. 1, p. 15-36, 1987

\section{Endereço para correspondência}

Leopoldino Capelozza Filho

Rua Sérvio Túlio Carrijo Coube 2-70

CEP: 17012-632

Bauru - SP

e-mail: Icapelozza@uol.com.br 